Price TRP (1981): Unilateral electroconvulsive therapy for depression. $N$ Engl J Med 304:53.

Raskin A, Schulterbrandt J, Reatig N, McKeon J (1969): Replication of factors of pathology in interview, ward behavior, and self-report ratings of hospitalized depressives. J Nerv Ment Dis 148:87-98.

Roades HM, Overall JE (1983): The Hamilton depression scale: Factor scoring and profile classification. Psychopharm Bull 19:91-96.

Small IF, Small JG, Milstein V (in press). Electroconvulsive therapy. In Berger PA, Brodie HKH (eds), American Handbook of Psychiatry, Vol VIII, 2nd ed. New York: Basic Books.

Small JG, Small IF (1981): Electroconvulsive therapy update. Psychopharm Bull 17:29-42.

\section{"Paradoxical" Shortening of REM Latency on First Recording Night in Major Depressive Disorder: Clinical and Polysomnographic}

\section{Correlates}

Marc Ansseau, David J. Kupfer, Charles F. Reynolds III-and Patricia A. Coble inpatients with major depressive disorders, variability in REM latency $(R L)$ mights was assessed by means of an "adaptation coefficient" during the first two recording nights was assessed by means of an 1 and 2). Although mean $(A C=$ night $1 R L-$ night $2 R L \times 100 \div$ mean $5 L$ min), individual ACs showed a $R L$ was very similar for both nights (48.1 and 50.7 min), individual ACs 4 . Fl. Fortygaussian distribution [range: $-176.5-171.4$; mean: $-1.2(67.3)$; median: -4.4 ] Fortytwo patients $(45.7 \%)$ exhibited shortening of $R L$ on night 2 compared with night 1 (positive $A C$, corresponding to an "expected" evolution), 48 patients (52.2\%) displayed the opposite pattern (negative AC, corresponding to a "paradoxical" evolution), and two posite pattern. (ne gath increase in $R L$ from first to second patients had identical values on both" evolution) correlated significantly with increasing night (i.e., extent of "paradoxical" evolution) correlated significanly wich in to tricyclic duration of current episode, earlier age of onset, and poorer clinical response to tricyclic antidepressants. A cutoff AC of -7 correctly classified $62 \%$ of patients according to treatment response. The research diagnostic criteria-based retarded subtyp" ovolution), sion was associated with a more negative AC (i.e., a more "paradoxical (i.e., a more "exand the situational subtype was associated with a more positive AC (i.e., a more and the siturion) than the remainder of the sample. The subgroup with th

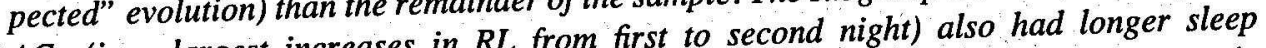
$A C s$ (i.e., largest increases in RL from the di.e., largest decreases in latencies, whereas the subgroup with the most positive ACs (i.e the remainder of the $R L)$ had higher REM activity and REM density as compared with the remaind sample. These results suggest that $R L$ in major depression is not a static parameter and that the These resuls sithin-subject variability can be helpful for diagnostic confirmation and prediction of treatment response.

niversity of Pittsburgh School of Medicine, . Pelgium. Pent address (M.A.). Psychopharmacology Unit

(1) Address reprint requests to: David J. Kupfer, M.D., Department of Psychiatry, Wesnsylvania 15213.

Received June 17, 1984; revised August 1, 1984. 


\section{Introduction}

Many sleep researchers have described a so-called first-night effect, defined as the influence of the environmental and technical conditions of the sleep laboratory on data collected during the first night. The effect occurs both in normal subjects (Rechtschaffen and Verdone 1964; Agnew et al. 1966; Mendels and Hawkins 1967; Kales et al. 1967; Hartmann 1968; Schmidt and Kaelbling 1971; Coble et al. 1974; Webb and Campbell 1979; Browman and Cartwright 1980; Spiegel 1981; Balestra et al. 1983; Rosadini et al. 1983 ) and in psychiatric patients (Mendels and Hawkins 1967; Kupfer et al. 1974, 1982; Reynolds et al. 1982). This first-night effect generally includes a longer sleep latency, less time spent asleep, decreased delta sleep time and REM time, and an increased number of awakenings and stage changes. Probably the most consistent finding, however, is a first-night increase of REM latency (RL) compared with subsequent nights. First-night effects seem to increase with age (Webb and Campbell 1979); the importance of a "comfortable hotel-type environment" and of a "friendly and open staff" to minimize the incidence of these effects has been stressed (Coble et al. 1974; Browman and Cartwright 1980). A recent study, however, failed to demonstrate any significant difference between first- and second-night sleep parameters in 30 patients evaluated for impotency (Kader and Griffin 1983), suggesting that first-night effects may not be ubiquitous.

As already noted by Mendels and Hawkins (1967), Kupfer et al. (1974) suggested that the sleep of depressive inpatients was less disturbed during adaptation nights than the sleep of normal subjects. This finding was confirmed and extended by outpatien studies conducted by Coble et al. (1976) and Akiskal et al. (1982), showing that primary depressives differed strikingly from secondary depressives by their absence of adaptational changes in RL. Contradictory results were obtained by Reynolds et al. (1982) showing that, while 20 primary depressive inpatients did not present first-night effects on any sleep parameter, age-matched outpatients with the same diagnosis exhibited evidence of adaptation to the laboratory, with greater amounts of REM sleep time and activity on night 2 than on night 1 . The outpatients' $R L$ was longer (but not significantly) on night 1 than on night 2 (56.9 vs $47.6 \mathrm{~min}$ ).

The relative absence of adaptational sleep changes does not seem specific to depressive disorders (or to some categories of depressive patients): 10 outpatients with generalized anxiety disorder showed the same stability in RL values from first to second night as a comparable group of outpatient depressives (Reynolds et al. 1983a). Moreover, anxiety disorder patients exhibited more stability of other electroencephalographic (EEG) sleep indexes for the first two nights. In the same way, 8 of 10 borderline patients showed stable mean RLs across the two recording nights, but the within-subject variability in the change of RL from night 1 to night 2 suggested the possibility that borderline patients might represent a heterogeneous group (McNamara et al. 1984).

Variability in RL across the first two recording nights has been found in preliminary studies to differ dramatically according to subgroup of depressives: Whereas a unipolar nonpsychotic group ( $n=12$ ) exhibited very stable values (54.2 and $54.3 \mathrm{~min})$, unipolar psychotic $(n=7)$ and bipolar nonpsychotic $(n=5)$ depressives presented a "paradoxical" increase in RL on the second night (17.8 vs. $32.7 \mathrm{~min}$ and 31.7 vs. $41.3 \mathrm{~min}$, respectively) (Kupfer et al. 1974).

Given this diversity of findings, the purpose of the current study was to reassess the first-night effect on the RL of a large sample of depressive inpatients and to determine possible correlates of "expected" vs. "paradoxical" variability in RL for the first two recording nights. It was previously suggested that direction of evolution "might have broader implications in the diagnostic evaluation of depressed patients" (Kupfer et al. broader implications in the diagnesting that the stability of biological correlates of major 1974). Essentially, we are suggesting that the stability of biological correlates of major depression, such as REM latency, continues to be an important issue. In fact, variability in REM latency has been little studied to date, particularly within-subject variability. The in REM latency has been linical significance of such within-subject variability, as it may relate to depossible clinical significance of such within-subject variability, as it mastic factors, natural history of disease, diagnostic subtyping, and prediction of treatment response, deserves careful assessment.

\section{Subjects and Methods}

\section{Sample and Procedure}

The characteristics of the sample and the evaluation and treatment procedures have been described in detail elsewhere (Ansseau et al. 1984). Briefly, 92 inpatients at the Clinical 列


The participants represented consecutive admissions who met research diagnostic criteria (RDC) for a major depressive disorder, according to the lifetime version of the Schedule for Affective Disorders and Schizophrenia (SADS-L) (Spitzer and Endicott 1977), and who had a score of at least 30 on the Hamilton Rating Scale for Depression (using the sum of two raters) at the end of a 2-week drug-free period.

All-night polygraphic sleep recordings were obtained for four consecutive nights and All-night poly were scored according to the Rechtschaffen-Kales criteria (1968). Studis were perforved during the third week of hospitalization, following a psychotropic-drug-free interval of at least 14 days and entrainment to ward schedule. Sleep onset was defined by the first minute of stage 2 sleep followed by at least $10 \mathrm{~min}$ of stage 2 sleep, interrupted by no minute of stage 2 sleep followe the the more than 2 min of awake or stage 1; REM latency corresponded to the time betwe sleep onset and first REM period ( $3 \mathrm{~min})$ minus any intervening wake time. Patients were treated with either amitriptyline $(n=73)$ or nortriptyline $(n=19)$ under double-blind conditions; the dosage of nortriptyline was one-half that of amitriptyline. For a period of 23 days, patients received, in stepwise fashion, 50-200 $\mathrm{mg}$ of amitriptyline and 25-100 mg of nortriptyline. The Hamilton Rating Scale for Depression, Brief Psychiatric Rating mg of nortriptyline. The Heck we throughout Scale (BPRS), Raskin Rating Scale, and Beck Randers $(n=57)$ if their final Hamthe study. Patients were defined as (1) treatment responders $(n=57)$ if their final Hamilton score (two-rated sum) was 19 or less and their decrease in baseline Hamilton score was at least $40 \%$; (2) nonresponders $(n=25)$ if their final Hamilton score was 20 or (3) "indeterminate" higher and their decrease in the responders $(n=10)$ in any oth

The study included 31 male and 61 female patients, ranging in age from 18 to 69

The study included 31 male and 6 (mean: $36.5 \pm 12.6$ ). The characteristics of the sample according to the RDC subtypes are displayed in Table 2 .

Data Analysis

Change in RL across the first two recording nights was calculated as an index corresponding to night $1 \mathrm{RL}-$ night $2 \mathrm{RL} \times 100 \div$ mean RL for nights 1 and 2 . This coefficient, referred to hereafter as the adaptation coefficient (AC), controls for the effect 
of RL duration on internight variability. The relationship between $\mathrm{AC}$ and clinical parameters having continuous distribution was assessed by the Pearson correlation coefficient. The sample was then stratified into three equal subgroups according to AC: (1) 31 patients with the most negative $\mathrm{AC}(<-21)$, i.e., the most "paradoxical" evolution; (2) 30 patients with intermediate $A C$ (from -21 to +17 ); and (3) 31 patients with the most positive $(>17)$, i.e., the most "expected" evolution. Clinical characteristics having continuous distribution and severity ratings were compared among the three groups using univariate analysis of variance (ANOVA). To test for differences in the hand-scored sleep data among the three groups, a two-factor analysis of variance (using group and night as factors) with repeated measures (the four recording nights) was run for each variable. A posteriori nonorthogonal contrasts were then made using the Newman-Keuls comparison procedure. The AC in subgroups defined by gender or RDC subtypes was compared with the $\mathrm{AC}$ of the remainder of the sample using univariate ANOVA. When subgroup variances differed significantly, the ANOVA was adjusted by the Brown-Forsythe statistic.

\section{Results}

\section{Evolution of $R L$}

In this sample of 92 depressive inpatients, the mean (SD) RLs on nights 1 and 2 were very similar: $48.1 \mathrm{~min}$ (24.9) on night 1 (range: 2-123 min; median: $50.5 \mathrm{~min}$ ); and 50.7 min (32:1) on night 2 (range: $3-167$ min; median: $50 \mathrm{~min}$ ).

Among the 92 patients, 42 (45.7\%) exhibited a shortening of RL on night 2 as compared with night 1 (expected evolution), 48 patients $(52.2 \%)$ exhibited the opposite evolution (paradoxical evolution), and two patients $(2.2 \%)$ showed identical values for both recording nights. The distribution of RL changes between nights 1 and 2 , as expressed by the $\mathrm{AC}$ (Figure 1), was gaussian, with the $\mathrm{AC}$ ranging from -176.5 to 171.4 [mean (SD): - 1.2 (67.3); median: -4.4].



Figure 1. Distribution of night 1-2 changes in REM latency, measured by the adaptation coefficient in 92 major depressive inpatients. $A C=$ night $1 \mathrm{RL}-$ night $2 \mathrm{RL} \times 100 \div$ mean $\mathrm{RL}$ for nights 1 and 2 . A positive AC represents a "expected" evolution and a negative AC a "paradoxical" evolution.

\section{Clinical and Polysomnographic Correlates}

With regard to clinical characteristics and severity ratings, the AC showed a significant correlation with age of onset of depressive illness $(r=0.21 ; p<0.05)$, indicating that the extent of increase in RL from first to second night (i.e., the extent of "paradoxical" evolution) correlated inversely with age of onset: thus the greater the increase, the earlier the age of onset. Inverse relationships were found between $\mathrm{AC}$ and duration of current episode $(p<0.05)$, as well as with final scores on the Hamilton Depression $(p<0.05)$, Raskin $(p<0.001)$, and Brief Psychiatric Rating Scales $(p<0.01)$ (Table 1). In other words, the extent of increase in RL from first to second night (i.e., extent of "paradoxical" evolution) showed a significant correlation with increasing duration of current episode and poorer symptomatic improvement after pharmacological treatment. In no instance, however, was a significant correlation found between a baseline severity rating (Hamilton, Raskin, BPRS, or Beck) and the adaptation coefficient (see Table 1).

With respect to clinical response to tricyclic antidepressants, treatment responders were characterized by a positive mean AC (i.e., an "expected" evolution) and nonresponders by a negative mean $\mathrm{AC}$ (i.e., a "paradoxical" evolution), which differed significantly $(p<0.05)$. Discriminant analysis using a jackknife classification showed that an AC ( $p<$ correctly classified $61 \%$ of responders and $64 \%$ of nonresponders cutoff value of -70.05 ). With regard to gender and RDC subtypes, the retarded subtype was associated with a significantly more negative AC (i.e., with a more "paradoxical" was associated with a sample $(p<0.05)$. By contrast, the situal ?

Table 1. Relationship Between REM Latency Adaptation Coefficient and Clinical Characteristics or Severity Ratings ${ }^{a-c}$

\begin{tabular}{lc}
\multicolumn{1}{c}{ Parameter } & $r$ \\
\hline Clinical characteristic & \\
Age & 0.19 \\
Age at first onset & $0.21^{d}$ \\
Illness duration & -0.02 \\
Number of episodes & -0.08 \\
Duration of current episode & $-0.24^{d}$ \\
& \\
$\quad$ Severity ratings & 0.16 \\
Baseline Hamilton & $-0.21^{d}$ \\
Final Hamilton & 0.04 \\
Baseline Raskin & $-0.34^{e}$ \\
Final Raskin & 0.09 \\
Baseline BPRS & $-0.27^{f}$ \\
Final BPRS & -0.03 \\
Baseline Beck & -0.15 \\
\hline Final Beck &
\end{tabular}

${ }^{a A C}$, adaptation coefficient; BPRS, Brief Psychiatric Rating Scale; RL, REM latency.

${ }^{b} \mathrm{AC}=$ night $1 \mathrm{RL}-$ night $2 \mathrm{RL} \times 100 \div$ mean $\mathrm{RL}$ for nights 1 and 2.

Pearson correlation coefficient.

${ }_{i}<0.05$.

${ }_{i p} p<0.05$.
$e_{p}<0.001$

$f_{p}<0.01$. 
subtype had a significantly more positive AC (i.e., a more "expected" evolution) $(p<0.05)$ (see Table 2).

Comparison of the three subgroups, defined according to $\mathrm{AC}$, with respect to clinical characteristics (see Table 3 ) showed higher final Raskin $(p<0.05)$ and BPRS $(p<0.05)$ scores in the patients with the largest increase in RL from first to second night. This analysis was consistent with the previous finding of a positive $\mathrm{AC}$ among treatment responders, but a negative $\mathrm{AC}$ among nonresponders.

For the same three subgroups, comparison of sleep characteristics from the four recording nights (see Table 4 ) indicated that the subgroup with the largest increase in RL from first to second night had the longest sleep latencies $(p<0.01)$. By contrast, the subgroup with the largest decrease in RL had higher REM activity $(p<0.01)$ and REM density $(p<0.05)$ than did the other two subgroups.

Discussion

The results of this study show that the sleep of major depressive inpatients is characterized by a very similar mean RL during the first two recording nights. This finding confirms previous reports (Mendels and Hawkins 1967; Kupfer et al. 1974; Reynolds et al. 1982) of a lack of first-night effect on RL in major depression. However, the present study does not support the conclusion reached by Coble et al. (1976) and Akiskal et al. (1982) of a striking difference between primary and secondary depressives with regard to their RL evolution, with primary depressives showing no evidence of a first-night effect and secondary depressives presenting adaptational changes similar to those made by normal subjects. The present study shows similar stability of RL in both subgroups. A possible explanation for this discrepancy is that the studies conducted by Coble and Akiskal and their associates involved outpatients, instead of inpatients as in the present study. This difference could be a confounding factor, as suggested by the data of Reynolds et al. (1982), which indicated that outpatients with primary depression are more sensitive to

Table 2. Relationship Between REM Latency Adaptation Coefficient and Gender, Clinical Response, and RDC Subtype in Major Depressives ${ }^{a, b}$

\begin{tabular}{|c|c|c|c|c|}
\hline Variable & Number & Comparison of AC & $F$ & $p$ \\
\hline Male/Female & $31 / 16$ & $-3.2(82.9) /-0.1(58.7)$ & 0.0 & NS \\
\hline Responders/Nonresponders ${ }^{c}$ & $57 / 25$ & $9.2(64.4) /-23.6(73.4)$ & 4.1 & $<0.05$ \\
\hline Primary/Secondary & 68.24 & $-3.2(68.1) / \quad 2.5(63.1)$ & 0.1 & NS \\
\hline Recurrent & $57^{d}$ & $0.1(70.7) /-3.3(62.4)$ & 0.1 & NS \\
\hline Psychotic & $6^{d}$ & $-8.7(42.8) /-0.7(68.9)$ & 0.1 & NS \\
\hline Incapacitating & $82^{d}$ & $0.2(68.7) /-12.4(56.9)$ & 0.3 & NS \\
\hline Agitated & $45^{d}$ & $10.4(68.9) /-12.2(64.6)$ & 2.6 & NS \\
\hline Retarded & $46^{d}$ & $-15.9(74.2) / \quad 13.5(56.7)$ & 4.6 & $<0.05$ \\
\hline Situational & $54^{d}$ & $11.5(56.8) /-19.3(77.2)$ & 4.9 & $<0.05$ \\
\hline Simple & $48^{d}$ & $1.6(64.1) /-4.2(71.3)$ & 0.2 & NS \\
\hline Unipolar & $83^{d}$ & $-0.5(69.4) /-8.2(43.0)$ & 0.1 & NS \\
\hline Bipolar I & $4^{d}$ & $-25.2(9.2) /-0.1(68.6)$ & 0.5 & NS \\
\hline Bipolar II & $5^{d}$ & $12.2(51.4) / \quad-2.0(68.3)$ & 0.2 & NS \\
\hline
\end{tabular}

${ }^{a} \mathrm{AC}$, adaptation coefficient; RDC, research diagnostic criteria; RL, REM latency.

${ }_{\mathrm{AC}}=$ night $1 \mathrm{RL}-$ night $2 \mathrm{RL} \times 100 \div$ mean RL for nights 1 and 2 .

A third group were indeterminate responders, consisting of 10 patients.

${ }^{d}$ Compared with the remainder of the sample.
Table 3. Selected Clinical Characteristics Among Three Subgroups of Major Depressives Defined According to REM Latency Adaptation Coefficient ${ }^{a, b}$

\begin{tabular}{|c|c|c|c|c|c|}
\hline Parameter & $\begin{array}{l}\text { Negative } \\
\text { AC }^{c}\end{array}$ & $\begin{array}{c}\text { Intermediate } \\
\mathbf{A C}^{d}\end{array}$ & $\begin{array}{c}\text { Positive } \\
\mathrm{AC}^{e}\end{array}$ & $F$ & $p$ \\
\hline & \multicolumn{2}{|c|}{ Clinical characteristics } & & & \\
\hline Age & $33.5(12.8)$ & $38.0(13.5)$ & $37.9(11.3)$ & 1.3 & NS \\
\hline Age at first onset & $25.4(11.8)$ & $28.2(14.3)$ & $28.7(12.5)$ & 0.6 & NS \\
\hline Number of episodes & $2.6(2.3)$ & $2.9(2.2)$ & $2.5(2.4)$ & 0.2 & NS \\
\hline Duration of current episode (weeks) & $77.3(78.9)$ & $59.4(80.7)$ & $43.9(45.0)$ & 1.8 & NS \\
\hline & \multicolumn{2}{|c|}{ Severity ratings } & & & \\
\hline Baseline Hamilton & $34.2(9.6)$ & $32.2(9.9)$ & $\begin{array}{r}36.8(11.5) \\
\cdot 15.3(10.1)\end{array}$ & $\begin{array}{l}1.5 \\
1.5\end{array}$ & $\begin{array}{l}\text { NS } \\
\text { NS }\end{array}$ \\
\hline Final Hamilton & $18.9(9.6)$ & $14.4(12.2)$ & & & NS \\
\hline $\begin{array}{l}\text { Baseline Raskin } \\
\text { Final Raskin }\end{array}$ & $\begin{array}{r}10.2(1.8) \\
7.8(1.5)\end{array}$ & $\begin{array}{l}9.3(1.9) \\
6.7(2.3)\end{array}$ & $\begin{array}{r}10.1(2.2) \\
6.6(2.5)\end{array}$ & $\begin{array}{l}2.1 \\
4.0\end{array}$ & $\begin{array}{l}\text { NS } \\
<0.05\end{array}$ \\
\hline $\begin{array}{l}\text { Baseline BPRS } \\
\text { Final BPRS }\end{array}$ & $\begin{array}{l}12.2(5.0) \\
10.4(5.8)\end{array}$ & $\begin{array}{r}11.2(4.4) \\
7.6(5.4)\end{array}$ & $\begin{array}{r}12.3(4.5) \\
7.4(4.9)\end{array}$ & $\begin{array}{l}0.5 \\
2.9\end{array}$ & $\begin{array}{c}\text { NS } \\
<0.05\end{array}$ \\
\hline $\begin{array}{l}\text { Baseline Beck } \\
\text { Final Beck }\end{array}$ & $\begin{array}{l}18.1(8.1) \\
13.5(7.5)\end{array}$ & $\begin{array}{l}16.2(7.3) \\
10.0(8.1)\end{array}$ & $\begin{array}{l}18.1(7.9) \\
11.4(7.6)\end{array}$ & $\begin{array}{l}0.6 \\
1.5\end{array}$ & $\begin{array}{l}\text { NS } \\
\text { NS }\end{array}$ \\
\hline
\end{tabular}

aAC adaptation coefficient; BPRS, Brief Psychiatric Rating Scale; RL, REM latency.

${ }^{\mathrm{A} C}=$ night $1 \mathrm{RL}-$ night $2 \mathrm{RL} \times 100 \div$ mean RL for nights 1 and 2

${ }^{b} \mathrm{AC}=$ night $1 \mathrm{RL}-$ night $2 \mathrm{RL} \times 100 \div$ mean
$<<-21(n=31)$, the most paradoxical evolution.

$d-21$ to $+17(n=30)$.

$>17(n=31)$, the most expected evolution.

the first-night effect than inpatients. Moreover, the differences in sleep architecture noted by Coble et al. (1976) and Akiskal et al. (1982) between primary and secondary depressives may reflect an epiphenomenon of sample differences in age, severity, or percentage of patients with endogenous depression, as no EEG sleep abnormalities were found to differentiate age- and severity-matched primary and secondary inpatients (Thase found to differe
et al. in press).

In fact, the stable mean RL for this whole sample of depressives from first to second recording nights conceals considerable within-subject variability in RL evolution, with about half the patients exhibiting longer RL on night 1 than on night 2 and the other half the opposite pattern. Unexpectedly, we observed a normal distribution in the ratio parameter of RL evolution (expressed as AC) from night 1 to night 2-a distribution more similar to the typically gaussian distribution of nonratio EEG sleep parameters in depression (e.g., time spent asleep or REM activity units) than to the nonnormal distribution of ratio parameters (e.g., sleep efficiency or REM density). Further, "paradoxical" shortening of RL on the first recording night compared with the following night is associated with a younger age of onset of depressive illness, a longer duration of the current depressive episode, and a worse response to tricyclic antidepressant therapy, as evidenced by the more negative ACs in the treatment nonresponder subgroup and by the inverse relationship between $\mathrm{AC}$ and final rating scale scores (i.e., highest final severity ratings in the group with the most negative AC). Previous studies of EEG sleep as predictor of treatment response in depression showed prolonged REM latency and reduced sleep latency following a pharmacological challenge with amitriptyline to be the main sleep variables differentiating responders from nonresponders (Kupfer et al. 1976, 1980, 1981). In a 
Table 4. Selected Sleep Characteristics Among Three Subgroups of Major Depressives Defined by REM Latency Adaptation Coefficient ${ }^{a-c}$

\begin{tabular}{|c|c|c|c|c|c|}
\hline Sleep characteristic & $\begin{array}{c}\text { Negative } \\
\text { AC }\end{array}$ & $\begin{array}{l}\text { Intermediate } \\
\text { AC }\end{array}$ & $\begin{array}{l}\text { Positive } \\
\text { AC }\end{array}$ & $F$ & $p$ \\
\hline & & Sleep continuity & & & \\
\hline Sleep latency (min) & $44.5(27.8)$ & $31.7(24.6)$ & $34.1(18.8)$ & 4.9 & $<0.01$ \\
\hline Time spent asleep (min) & $341.4(45.0)$ & $336.0(47.1)$ & $344.4(45.0)$ & 0.5 & NS \\
\hline Sleep efficiency ${ }^{d}(\%)$ & $84.1 \quad(9.6)$ & 83.0 (11.4) & $84.1 \quad(9.5)$ & 0.2 & NS \\
\hline Sleep maintenance $(\%)$ & $94.4(7.8)$ & $90.2(11.3)$ & $91.8 \quad(9.3)$ & 2.2 & NS \\
\hline & & Sleep architecture & & & \\
\hline Stage $2(\%)$ & $62.7 \quad(8.7)$ & $65.5(8.6)$ & $61.9(7.8)$ & 2.2 & NS \\
\hline Stages 3 and $4(\%)$ & $3.0 \quad(5.2)$ & $2.5(4.8)$ & $1.7(3.1)$ & 0.7 & NS \\
\hline Stage REM (\%) & $24.8 \quad(7.0)$ & $24.5(6.1)$ & $26.5 \quad(6.3)$ & 1.3 & NS \\
\hline$\ldots$ & & REM measures & & & \\
\hline REM latency (min) & $49.7(31.9)$ & $53.0(24.6)$ & $46.4(26.7)$ & 0.6 & NS \\
\hline REM activity (units) & $107.4(57.6)$ & $98.5(42.4)$ & $137.0(62.7)$ & 5.9 & $<0.01$ \\
\hline REM density $f$ & $1.25(0.49)$ & $1.19(0.42)$ & $1.49(0.51)$ & 4.2 & $<0.05$ \\
\hline Number of REM periods & $3.6(0.8)$ & $3.5(0.8)$ & $3.6(0.7)$ & 0.3 & NS \\
\hline
\end{tabular}

${ }^{a} \mathrm{AC}$, adaptation coefficients; RL, REM latency; SD, standard deviation.

${ }^{b} \mathrm{AC}=$ night $1 \mathrm{RL}-$ night $2 \mathrm{RL} \times 100 \div$ mean $\mathrm{RL}$ for nights 1 and 2

Mean of four consecutive nights \pm SD:

Time spent asleep $\div$ total recording period

Time spent asleep $\div$ total recording period - sleep latency.

REM activity $\div$ REM time.

small sample, a mean cutoff level of $10 \%$ REM reduction during the first two nights of amitriptyline administration (150-200 mg) correctly classified $82 \%$ of the patients and the addition of a REM latency change of greater than $100 \mathrm{~min}$ increased the correct identification to $88 \%$ (Kupfer et al. 1976). Even if the treatment response prediction of $\mathrm{AC}$ in this study is somewhat lower (62\%), it must be emphasized that the collection of $\mathrm{AC}$ requires only two baseline night sleep recordings; moreover, $\mathrm{AC}$ may increase the performance of an eventual amitriptyline challenge.

We previously reported a significant inverse correlation between baseline REM latency (averaged over two or more nights of sleep) and Hamilton severity ratings (Reynolds et al. 1983b), suggesting that greater symptomatic severity of depression is correlated with shortening of REM latency. In the present study, however, we found no significant correlations between $\mathrm{AC}$ and baseline clinical ratings (Table 1) on the Hamilton, Raskin, Beck, and BPRS scales, while at follow-up, AC was significantly correlated with three of the four measures (Hamilton, Raskin, and BPRS). Apparently, in contrast to baseline averaged REM latency data, the measure of within-subject REM latency variability used in this study (adaptation coefficient) does not correlate with baseline severity ratings, even though it significantly correlates with final severity ratings and predicts treatment response to a degree greater than would be expected on the basis of chance alone. There is no obvious explanation for this finding, which requires independent confirmation.

With regard to differential evolution of $\mathrm{RL}$ according to clinical subtypes of depression, this study confirms the earlier observation made by Kupfer et al. (1974) of complete stability of mean RL in the unipolar subgroup (mean AC: -0.05 ) and the trend to a shortening of $\mathrm{RL}$ on night 1 in the psychotic $(\mathrm{AC}=-8.7)$ and bipolar $\mathrm{I}(\mathrm{AC}=-25.2)$ show number of psychotics and bipolar I patients included in this sample, none of those RDC subgroups present a statistically patients included in this sample, no remainder of the sample. On the other hand, the retarded subtype is associated with significantly more "paradoxical" RL evolution, whereas the sirece of the sample. The relationship noted between "paradoxical" evolution and retarded subtype of depression may explain the association between bipolar depression and "paradoxical" RL suggested by Kupfer et al. (1974) and also observed in the present study. Indeed, bipolar depressives exhibit symptoms of retardation, anergia, and hypersomnia more consistently than do unipolar depressives (Detre et al. 1972; Kupfer et al. 1972; Depue and Monroe 1978; Kupfer et al. 1978; Duncan et al. 1979).

In this study, the subgroup with the more "expected" evolution of RL shows higher REM activity and REM density than is exhibited by the other subgroups. Many studies REM activity and REM density than is exhibited by the other, REM activity and REM have shown that, compared with normals or patient controls, REM activity and REM density are increased in primary or endogenously depressed patients (Coble et al. 1976; Foster et al. 1976; Kupfer et al. 1978; Gillin et al. 1979; King et al. 1981; Kupfer 1981; Foinberg et al. 1982) and decreased in many patients with depression secondary to medical or neurological illness (Foster et al. 1976; Fink et al. 1977; Kupfer et al. 1978; King et or 1981). Moreover, REM density may be the sleep parameter that remains the mos al. 1981). Moreover, REM density may be the symptoms (Schultz and consistently abnormal even after clinical remission of depressive symptoms (Schult $z$ and Trojan 1979; Kupfer 1982; Gillin et al. 1982) and therefore may represent a potential trait marker of depression. This hypothesis is supported by a recent study of Coble et al. (personal communication) showing that despite the similarity between other sleep param(personal communication) showing that distory of affective disorder differ from children eters, healthy children with a family history of affective disorder differ from children with a negative family history by higher REM activity and REM density. Thus, these data suggest the possibility that the patient with the most "expected" evolution in RI" represent one genetically distinct subgroup, whereas those with the most "paradoxical" represent another (e.g., bipolars). This hypothesis could be tested by assessing the composition of the different subgroups according to the genetic classification of depression proposed by Winokur et al. (1978).

The increased sleep latency in the "paradoxical" RL subgroup may reflect the poorer clinical response noted in this group. For example, Kupfer et al. (1976) found a slightly longer sleep latency in the baseline sleep recordings of nonresponders to amitriptyline long ( 56.3 vs. $43.1 \mathrm{~min}$ ), as well as a lower REM activity (126.3 vs. than in responders ( 56.3 vs. $43.1 \mathrm{~min})$, as well as a lowe 166.0); these same trends are noted in the present study. However, none of these differences were statistically significant. Psychotic depressives also present longer sleep latency than do nonpsychotic depressives (Kupfer et al. 1978; Ansseau et al. 1984); however, they differ strongly from the "paradoxical" RL subgroup described in this study by their associated decrease in other sleep-continuity measures.

In conclusion, this study suggests that in major depression, individual RL is not a Whin-subject changes across consecutive nights should be taken into account in order to increase the clinical usefulness of RL in diagnostic confirmation and prediction of treatment response.

asstance in data management, to A.B. McEachran, whe data analysis, and to $\mathrm{K}$. Slomka and B. Bradbury fos their technical assistance. 


\section{References}

Agnew HW, Webb WB, Williams RL (1966): The first night effect: An EEG study of sleep. Psychophysiology 2:263-266.

Akiskal S, Lemmi H, Yeravanian B, King D, Belluomoni J (1982): The utility of the REM latency test in psychiatric diagnosis: A study of 81 depressed outpatients. Psychiatr Res 7:101-110.

Ansseau M, Thase M, Kupfer DJ, Taska L, Reynolds CF III (1984): EEG sleep in age- and gendermatched older psychotic depressives; non-psychotic depressives, and controls. Paper presented at the Seventh Congress of the European Sleep Research Society, Munich, 1984.

Balestra V, Ferrillo, F, Nuvoli GF, Rodriguez G, Rosadini G, Sannita WG (1983): Effects of adaptation to the sleep laboratory: II. Sleep parameters. In Koella WP (ed), Sleep 1982: Sixth European Congress of Sleep Research, Zurich 1982. Basel: Karger, pp 186-189.

Browman CP, Cartwright RD (1980): The first-night effect on sleep and dreams. Biol Psychiatry 15:809-812.

Coble P, Foster G, Kupfer DJ (1976): Electroencephalographic sleep diagnosis of primary depression. Arch Gen Psychiatry 33:1124-1127.

Coble P, McPartland RJ, Silva WJ, Kupfer DJ (1974): Is there a first night effect? (A revisit). Biol Psychiatry 9:215-219.

Depue RA, Monroe SM (1978): The unipolar-bipolar distinction in the depressive disorders. Psychol Bull 85:1001-1029.

Detre T, Himmelhoch JM, Swartzburg M, Anderson CM, Byck R, Kupfer DJ (1972): Hypersomnia and manic-depressive disease. Am J Psychiatry 128:123-125.

Duncan WC Jr, Pettigrew KD, Gillin JC (1979): REM architecture changes in bipolar and unipolar depression. Am J Psychiatry 136:1424-1427.

Feinberg M, Gillin JC, Carroll BJ, Greden JF, Zis AP (1982): EEG studies of sleep in the diagnosis of depression. Biol Psychiatry 18:305-316.

Fink M, Foster FG, Kupfer DJ, Spiker DG (1977): EEG sleep diagnosis of medical disease in depression. Neuropsychobiology 3:167-178.

Foster FG, Kupfer DJ, Coble P, McPartland RJ (1976): Rapid eye movement sleep density. Arch Gen Psychiatry 33:1119-1123.

Gillin JC, Sitaram N, Post RM, Wehr T (1982): Clues from sleep studies for transient and abiding pathophysiological mechanisms in affective illness. Cited in Kupfer DJ (1982).

Gillin JC, Duncan W, Pettigrew KD, Frankel BL, Snyder F (1979): Successful separation of depressed, normal, and insomniac subjects by EEG sleep data. Arch Gen Psychiatry 36:85-90.

Hartmann E (1968): Adaptation to the sleep laboratory and placebo effect. Psychophysiology 4:389.

Kader GA, Griffin PT (1983): Reevaluation of the phenomena of the first night effect. Sleep 6:67-71.

Kales A, Jacobson A, Kales JD, Kun T, Weissbuch R (1967): All-night EEG sleep measurements in young adults. Psychon Sci 78:67-68.

King D, Akiskal HS, Lemmi H, Wilson W, Belluomini J, Yerevanian BI (1981): REM density in the differential diagnosis of psychiatric from medical-neurologic disorders: A replication. Psychiatr Res 5:267-276.

Kupfer DJ (1981): Application of the EEG sleep in the treatment of depression, In Perris C, Kemali D, Vacca L (eds), Advances in Biological Psychiatry, Vol 6: Electroneurophysiology and Psychopathology. Basel: Karger, pp 87-93.

Kupfer DJ (1982): EEG sleep as biological markers in depression. In Usdin E, Hanin I (eds), Biological Markers in Psychiatry and Neurology. Oxford: Pergamon Press, pp 387-396.

Kupfer DJ, Himmelhoch JM, Swartzburg M, Anderson C, Byck R, Detre TP (1972): Hypersomnia in manic-depressive disease. A preliminary report. Dis Nerv Syst 33:720-724.)

Kupfer DJ, Weiss BL, Detre TP, Foster FG (1974): First night effect revisited: A clinical note. $J$ Nerv Ment Dis 159:205-209.

Kupfer DJ, Foster FG, Reich L, Thompson KS, Weiss B (1976): EEG sleep changes as predictors in depression. Am J Psychiatry 133:622-626.
Kupfer DJ, Foster FG, Coble PA, McPartland RJ, Ulrich RF (1978): The application of EEG sleep upfer DJ, Foster FG, Coble PA, McPartive disorders. Am J Psychiatry 135:69-74.

for DJ, Spiker DG, Coble PA, Neil JF, Ulrich R, Shaw DH (1980): Depression, EEG sleep, and clinical response. Compr Psychiatry 21:212-220.

Kupfer DJ, Spiker DG, Coble PA, Néil JF, Ulrich RF, Shaw DH (1981): Sleep and treatment prediction in endogenous depression. Am J Psychiatry 138:429-434.

Kupfer DJ, Reynolds CF III, Ulrich RF, Shaw DH, Coble PA (1982): EEG sleep, depression, and aging. Neurobiol Aging 3:351-360.

(II, Soloff PH, Mathias R, Rossi A, Spiker D, Coble PA, Kupfer DJ 1984): EEG sleep evaluation of depression in borderline patients. Am J Psychiatry 141:182-186. (1984): EEG sleep evaluation of depression in bordertation in normal subjects and depressed Mendels J, Hawkins DR (1967): Sleep laboratory adaptation in nom 22:556-558.

patients. First night effect. Electroencephalogr Clin Neurophysiol 22.556-S58.

Rechtschaffen A, Kales A (1968): A Manual of Standardized Terminology, Techniques, and Sco, US System for Sleep Stages of

Government Printing Office.

Rechtschaffen A, Verdone P. (1964): Amount of dreaming: Effect of inct

laboratory, and individual differences. Percept Motor Skills 19:947-958. Reynolds CF.III, Newton TF, Shaw DH, Coble PA, Kupfer DJ (1982

sleep findings in depressed outpatients. Psychiatr Res 6:65-72.

Reynolds CF III, Shaw DH, Newton TF, Coble PA, Kuper DJ (1983a). Eutpatients. Psychiatr Res with gen $8: 81-89$.

8:81-89. Reynolds CF III, Taska LS, Jarrett DB, Coble PA, Kupfer DJ

Is there one best definition? Biol Psychiatry 18:849-863. Rosadini G, Consoli D, Ferrillo F, Rodriguez G, Sannita wG, sion, quantitative EEG. Neuropsyadaptation to the sleep la
chobiology 10:178-182.

Scho differential laboratory adaptation of sleep parameters. Biol Psychiatry 33:33-45. (chulz H, Trojan depressed patients before and after remission. Sleep Res 8.49 . Spiegel R (1981): Sleep and Sleeplessness in Advanced Age. New York: Spectrum Publications. Spitzer RL, Endicott J (1977): Schedule for Affective Disorders and Schizophre ed. New York: New York State Psychiatric Intitute, Bomic criteria: Rationale and reliability. Spitzer RL, Endicott J, Robins E (1978)
Arch Gen Psychiatry 38:773-782.

Arch Gen Psychiarry $38.773-$ secosion

Psychiatry.
Webb WB, Campbell SS (1979): The first night effect revisited with age as a variable. Waking Sleeping 3:314-324.

Winokur G, Behar D, Van Valkenburg C, Lowry M (1978): Is a familial definition of depression both feasible and valid? J Nerv Ment Dis 166:764-768. 